\title{
The modification of attentional bias to emotional information: A review of the techniques, mechanisms, and relevance to emotional disorders
}

\author{
Michael Browning, Emily A. Holmes, and Catherine J. Harmer \\ University of Oxford, Oxford, England
}

\begin{abstract}
A negative bias in the deployment of attention to emotional stimuli is commonly found in both anxiety and depression. Recent work has highlighted that such biases are causally related to emotional vulnerability, suggesting that interventions that ameliorate them may be therapeutic. Here, we review the evidence that attentional bias can be modified using both pharmacological and psychological interventions. We highlight the behavioral and neuroimaging studies that suggest that these interventions impact upon attention via alteration of distinct neural mechanisms. Specifically, pharmacological interventions appear to influence the initial deployment of attention via an effect on the amygdala-based stimulus appraisal system, whereas psychological interventions influence attention at later time points and may alter activity in the lateral prefrontal cortex. Finally, we suggest a conceptual framework that embraces both pharmacological and psychological approaches and consider the possible implications of this work for future research and treatment development.
\end{abstract}

A wealth of data from behavioral, neuroimaging, pharmacological, and genetic studies has served to highlight the centrality of attentional processes in our understanding of anxiety and depression. Aberrant deployment of attention, particularly in relation to emotional information, occupies a pivotal position in many of the contemporary models of these disorders in which it is considered a causally relevant, proximal illness process. This view suggests that interventions that modify the habitual deployment of attention to emotional information should impact upon illness expression. In the present article, we will review the evidence that emotional attention may be modified in both experimental and clinical settings. In doing so, we will highlight the data that demonstrate that this modification may be achieved by targeting at least two distinct control mechanisms. Finally, we will consider the implications of this work, particularly with regard to future research and treatment development.

\section{What Evidence Links Abnormalities of Emotional Attention and the Emotional Disorders?}

Both depression and anxiety have been associated with biases in the processing of emotional information; patients with these disorders habitually interpret, attend to, and/or remember information in a more negative manner than do nonclinical control participants (Mathews \& MacLeod, 2005). Cognitive theorists suggest that these habits of thought are causal factors in the etiology and maintenance of the disorders (Beck, 1976; Mathews \& Mackintosh, 1998; Mathews \& MacLeod, 2005; Mogg \& Brad- ley, 1998; Williams, Watts, MacLeod, \& Mathews, 1997). Anxiety has particularly been associated with a tendency to attend to threatening information - a phenomenon that has been termed negative attentional bias (see Figure 1 for a summary of the tasks commonly used to assess attentional bias; Fox, Russo, \& Georgiou, 2005; MacLeod, Campbell, Rutherford, \& Wilson, 2004; Mathews \& MacLeod, 1985; Williams, Mathews, \& MacLeod, 1996). Recent work, much of it discussed in the body of this article, has employed simple computer-based tasks in order to induce attentional biases in nonclinical populations (for reviews, see MacLeod, Koster, \& Fox, 2009; Mathews \& MacLeod, 2002). Critically for psychopathology, these studies provide direct support for a causal role of attention in anxiety by demonstrating that inducing a negative attentional bias can lead to symptoms of anxiety in nonclinical participants.

In depression, the most consistent cognitive abnormalities were initially described in measures of memory (Gilboa-Schechtman, Erhard-Weiss, \& Jeczemien, 2002; Mathews \& MacLeod, 2005; Ridout, Astell, Reid, Glen, \& O'Carroll, 2003; Williams et al., 1997); however, there has been increasing interest in the possibility that attentional biases may exist in this disorder as well. Specifically, depression has been shown to be associated with a tendency to attend to the spatial location of negative words (Bradley, Mogg, \& Lee, 1997; Donaldson, Lam, \& Mathews, 2007; Mogg, Bradley, \& Williams, 1995) and faces (Gotlib, Kasch, et al., 2004; Gotlib, Krasnoperova, Yue, \& Joormann, 2004; Joormann \& Gotlib, 2007; Leyman, De Raedt, Schacht, \& Koster, 2007). Negative at- 
A

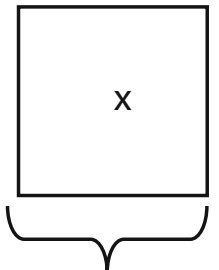

1,000

$\mathrm{msec}$

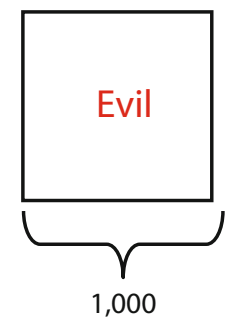

msec
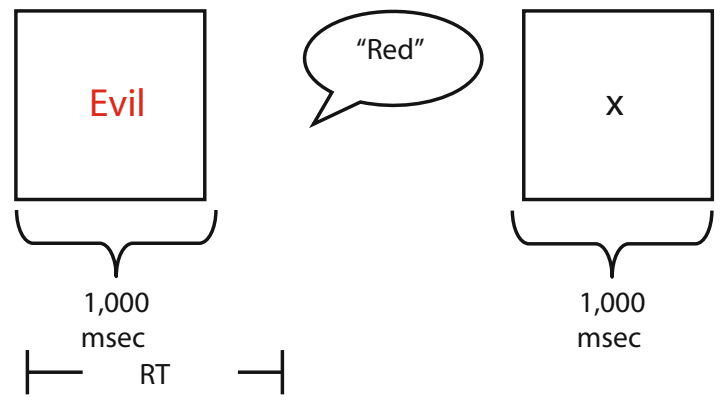

1,000

$\mathrm{msec}$

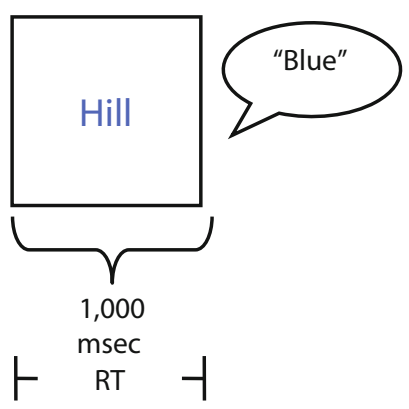

B
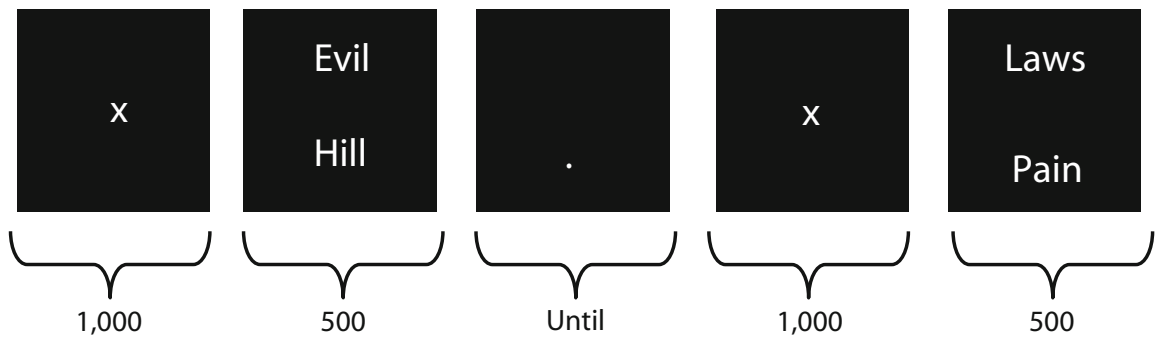

msec

500

msec
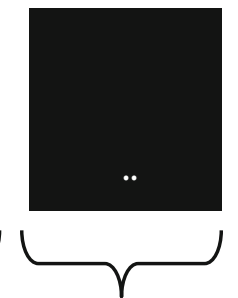

Until response
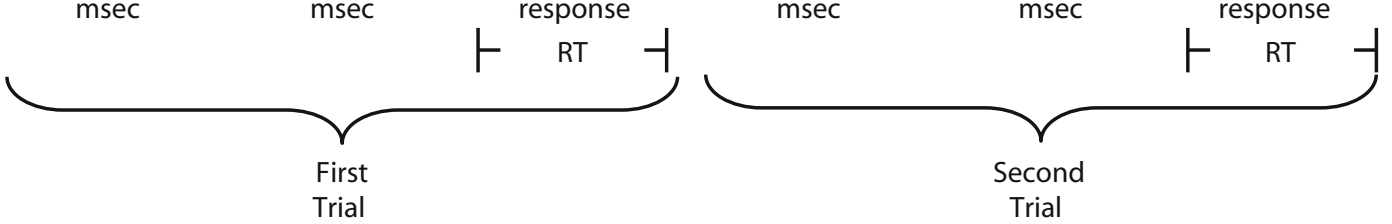

Figure 1. Behavioral methods of assessing emotional attention. Example trials from the two most common behavioral paradigms used to assess attentional function: the emotional Stroop (A) and visual probe (B) tasks. Behavioral tasks such as these are often the preferred method of assessing cognition, since they do not rely on the self-report of internal states, which is notoriously unreliable (Nisbett \& Wilson, 1977). During standard emotional Stroop tasks (A), participants are required to ignore the emotional content of a word stimulus while reporting its font color, the rationale being that the emotional aspect of the stimulus interferes with the required behavior and, therefore, lengthens reaction times. The demonstration of a specific lengthening of reaction times to emotional stimuli is argued to show that more processing resources (i.e., attention) have been captured by the stimuli (Williams, Mathews, \& MacLeod, 1996), although this interpretation has been disputed (Algom, Chajut, \& Lev, 2004; Larsen, Mercer, \& Balota, 2006). Emotional Stroop tasks are insensitive to the timing of attentional effects; instead, they provide a general indication that task interference has occurred at some point. The one exception to this is when masked stimuli are presented; in this case, the relevant stimulus is briefly presented and is followed by a nonemotional mask that prevents explicit identification of the stimulus. In such cases, it seems reasonable to assume that early stimulus appraisal processes lead to the task interference. Controversy in the interpretation of Stroop data has led to the increased popularity of visual probe tasks (B). On the basis of paradigms developed by Posner and colleagues (Posner \& Petersen, 1990), these have been argued to provide a purer estimate of spatial attention. The most common variety of this task involves the brief presentation of emotional and neutral stimuli, followed by a probe, to which the participant must respond, in the location of one of the stimuli (MacLeod, Mathews, \& Tata, 1986). It is assumed that reaction time is improved if attention is focused at the location in which the probe appears - that is, if the stimulus previously found at that location has captured attention. An estimate of attentional bias for emotional stimuli is calculated by comparing reaction times when the probe is found at the location of an emotional stimulus with those when it is found elsewhere. An advantage of visual probe tasks is that they provide information on the temporal characteristics of attention; specifically, they have been described as providing an estimate of attentional deployment at the time the probe is presented (Cooper \& Langton, 2006).

tentional biases are also demonstrable in previously depressed, currently euthymic patients (Joormann \& Gotlib, 2007), lending support to the proposal that they are involved in the vulnerability to depression rather than solely reflecting a state marker or symptom of the illness.

Although depression and anxiety have both been associated with attentional bias toward negative stimuli, there are differences in how this bias manifests between the disorders. Most obviously, there appears to be a variation in how long a stimulus must be presented before the bias becomes evident; whereas anxiety is associated with an attentional bias that occurs from 10 to $500 \mathrm{msec}$ after stimulus presentation, in depression the bias seems to occur between 500 and 1,000 msec (Gotlib, Kasch, et al., 2004). These timing effects are consistent with dualprocess accounts of brain organization that describe the 
existence of two distinct information-processing streams: an automatic stream that processes information in a rapid but inflexible manner and a strategic stream that provides slower, more flexible processing (see Carver, Johnson, \& Joormann, 2008, for a recent review of dual-process models relevant to the emotional disorders). It has been suggested (Mathews \& MacLeod, 2005) that anxiety is associated with abnormalities in the early, automatic processing of information and depression with abnormalities in later processing stages. In terms of attentional function, this may be reflected by abnormalities of the initial engagement of attention in anxiety, with difficulties in disengaging attention being characteristic of depression (Leyman et al., 2007; see also De Raedt \& Koster, 2010). Despite the differences seen in experimental paradigms, it is notable that individuals very often experience both anxious and depressive symptoms concurrently (Maser \& Cloninger, 1990; Mineka, Watson, \& Clark, 1998) and that there is a large overlap in the evidence-based treatments for these disorders (NICE, 2004, 2007). Thus, although there are some differences in the expression of attentional biases in anxiety and depression, there remains a strong possibility that these disorders share at least some pathological processes.

In summary, there is evidence that a tendency to preferentially attend to negative information is a feature of both anxiety and depression. Differences in the timing of the attentional biases found in depression and anxiety can be accounted for by dual-process models that postulate the existence of temporally separable attention control processes.

\section{What Processes Control Emotional Attention?}

The control of attention to emotional information is often conceptualized within a biased competition framework (Bishop, 2007; Desimone \& Duncan, 1995; Mathews \& Mackintosh, 1998; Vuilleumier, 2005). Broadly, this suggests that the deployment of attention is influenced by biasing signals that act to encourage the focus of attention toward or away from particular stimuli. Two neural systems have been implicated in generating signals of particular relevance to emotional stimuli. A bottom-up amygdalabased system generates a signal that reflects the perceived salience of stimuli (Adolphs, Tranel, Damasio, \& Damasio, 1995; Davis \& Whalen, 2001) and is thought to cause attention to be directed toward those stimuli. The anterior cingulate cortex (ACC) and lateral prefrontal cortex (IPFC) are considered to be part of a top-down control system that is involved in detecting and resolving processing conflict, with the result that attention may be maintained on relevant stimuli, even in the presence of distraction (Bishop, Duncan, Brett, \& Lawrence, 2004; MacDonald, Cohen, Stenger, \& Carter, 2000). These neuroanatomical models predict that the negative attentional biases characteristic of emotional disorder may arise from perturbation of either of these systems. Supporting this contention, experimental studies have reported increased amygdala activity to negative stimuli in both depression (Fales et al., 2008; Fu et al., 2004; Sheline et al., 2001; Siegle, Steinhauer, Thase, Stenger, \& Carter, 2002) and anxiety (Bishop, Duncan, \& Lawrence, 2004; Schneider et al., 1999; Shin, Rauch, \&
Pitman, 2006; Straube, Mentzel, \& Miltner, 2006; Tillfors, Furmark, Marteinsdottir, \& Fredrikson, 2002), whereas frontal activation to the same stimuli has been found to be decreased in both disorders (Bishop, Duncan, et al., 2004; Fales et al., 2008; Mayberg et al., 1999; Shin et al., 2001; although see also Straube et al., 2006; Tillfors et al., 2002). A notable discrepancy arises when these data are compared with those in the behavioral literature; whereas differences in the temporal characteristics of the biases associated with anxiety and depression are evident when assessed behaviorally (see above), neuroimaging studies do not seem to reliably differentiate the disorders. This may be due to constraints on the temporal resolution of functional imaging techniques or to the fact that neuroimaging studies have tended to simply present emotional stimuli without manipulating participants' attention (see Bishop, Duncan, et al., 2004, for an example of a study in which attention was manipulated). Such manipulations allow the effects of attention to be isolated from those due simply to the emotional properties of a stimulus. Nevertheless, the temporal specificity of the attentional effect demonstrated in the behavioral studies of anxiety versus depression remains unexplained by current neuroimaging data.

A further consideration when neuroimaging data are interpreted is that the biasing signals that influence attention seem to have direction as well as magnitude. For example, whereas depressed patients show decreased activity in the ACC during anticipation of loss, they show increased activation during anticipation of gain (Knutson, Bhanji, Cooney, Atlas, \& Gotlib, 2008). Similarly, amygdala activity is increased in response to positive stimuli in extroverted participants, as well as to negative stimuli in anxious individuals (Canli, Sivers, Whitfield, Gotlib, \& Gabrieli, 2002). These findings suggest that, rather than solely arising from an absolute alteration of function (e.g., decreased attentional control), emotional disorders may also reflect alterations in the valence of information to which the systems preferentially react (e.g., decreased attentional control for negative information and increased control for positive). Accordingly, the interventions reviewed in this article that alter attention to emotional information may be understood as altering this preference, rather than fundamentally changing the efficacy of the system.

Generally, however, the neuroimaging data complement the behavioral findings, in that the most commonly reported neuroimaging abnormalities in the emotional disorders would be expected to lead to negative attentional biases. These abnormalities - increased amygdala and decreased frontal activation in response to attended negative stimuli-are evident in both depression and anxiety and lead to the prediction that interventions that alter the function of either one or both of these systems will influence emotional attention and, in turn, current anxious and depressive symptomatology.

\section{Can the Effects of Treatment on Cognition Be Disentangled From the Effects of Mood?}

The interpretation of studies in which the effects of treatments on cognition are investigated can, paradoxi- 
cally, be hampered when the treatment is effective. The problem is particularly acute in studies of clinical populations, in which treatments are expected to improve clinical state. These studies inevitably compare groups that differ on two accounts: exposure to treatment (e.g., administration of an antidepressant vs. a placebo) and current levels of psychopathology (e.g., mood). Although such studies are essential when one is examining the effects of a treatment on the relevant population, it is difficult to be certain whether any differences observed in behavior or neural activity reflect the direct action of the intervention or are general effects of clinical status. The influence of this confounding factor can be reduced by studying nonclinical populations, who generally do not experience profound changes of mood and who can, thus, provide important complementary data to the clinical studies. Since the critical issue in the present article concerns the mechanisms by which treatments may work, we will consider both studies of clinical populations and those solely involving nonclinical participants.

\section{Pharmacological Methods of Modulating Attention to Emotional Information}

Neurochemical probes have been used to examine how neurotransmitter function may modulate attentional bias in both healthy volunteers and patients. One key strategy has been to see whether biases apparent in depression and anxiety can be mimicked by depletion of the neurochemicals known to be involved in these disorders.

Tryptophan depletion. The synthesis of serotonin in the brain is dependent on the availability of its precursor amino acid, tryptophan, from plasma. Acute administration of an amino acid mixture that selectively lacks tryptophan is effective in decreasing the availability of tryptophan to the brain through processes of increased protein synthesis (lowering plasma tryptophan levels) and increased competition for transport across the bloodbrain barrier (Reilly, McTavish, \& Young, 1997). Tryptophan depletion (TD) transiently lowers mood in recovered depressed patients, although there is no consistent effect on mood in healthy volunteers (Ruhe, Mason, \& Schene, 2007). Recently, however, TD has been used as an experimental tool for examining the role of serotonin in the processing of emotional information in healthy volunteers (Booij, Van der Does, \& Riedel, 2003). That TD is seen to affect cognition in nonclinical participants without altering mood suggests that cognitive measures, such as the attentional tasks examined in this article, provide a more proximal or, at least, more sensitive marker of the effects of this intervention than do mood measures. A number of studies (see Table 1) have suggested that reduction of serotonergic function using TD increases the interference associated with negative words in emotional Stroop tasks, both in never depressed populations (Evers, van der Veen, Jolles, Deutz, \& Schmitt, 2006) and in previously depressed ones (Hayward, Goodwin, Cowen, \& Harmer, 2005; Munafò, Hayward, \& Harmer, 2006). Interestingly, a study in which participants took tryptophan supplementation, an intervention predicted to increase serotonergic function, suggested that attention toward negative words was decreased in females (Murphy, Longhitano, Ayres, Cowen, \& Harmer, 2006). However, other studies have produced inconsistent results. First, in previously depressed participants, TD was found to slow responses in the emotional Stroop task to positive words, suggesting increased attentional interference from these positive cues (Booij et al., 2005). A further study showed no effect of TD on a visual-probe task involving threat-related words (Merens, Booij, Haffmans, \& Van der Does, 2008). Thus, although TD demonstrably influences the processing of emotional information, there is a degree of inconsistency to this effect.

Two neuroimaging studies have investigated the effects of TD on tasks in which emotional valence was manipulated, although neither explicitly manipulated attention. Both reported increased amygdala activation in response to negative stimuli following TD, although this effect was qualified by participant characteristics, which may explain some of the variance in the behavioral data. Thus, in a nonclinical sample, TD increased amygdala activity to fearful versus happy faces, but only in those with high scores on the behavioral inhibition subscale of the BIS/ BAS measure (Carver \& White, 1994; Cools et al., 2005). Similarly, a second study reported increased amygdala activation following TD in a group of healthy women, but only those with a family history of depression (van der Veen, Evers, Deutz, \& Schmitt, 2007).

Taken as a whole, these findings suggest that TD increases attention to negative emotional information and that its effect is associated with alteration of amygdala function; however, as has been noted with nonattentional measures of cognition (Robinson, Cools, Crockett, \& Sahakian, in press), this effect is qualified by individual differences in the participants.

Antidepressant administration. An alternative strategy in the investigation of the effects of neurotransmitter function on attentional bias is to characterize the effects of the pharmacological treatments of the emotional disorders. Sereotonergic function can be potentiated using antidepressant medications that specifically block the reuptake of serotonin from the synapse, a strategy recommended in the treatment of both depression and anxiety (NICE, 2004, 2007; Nutt, 2002). A number of experimental studies have assessed the influence of these serotonergic antidepressants on emotional attention in nonclinical groups (see Table 1). A single dose of the antidepressant citalopram was associated with an increased bias toward positive words in a visual-probe task (Browning, Reid, Cowen, Goodwin, \& Harmer, 2007), whereas 7 days of citalopram decreased attention to briefly presented fearful faces, an effect not seen with the norepinephric antidepressant reboxetine (Murphy, Yiend, Lester, Cowen, \& Harmer, 2009). As was predicted and contrary to the effects of TD, serotonergic antidepressants decreased amygdala activation to negative stimuli in both clinical (Fu et al., 2004; Sheline et al., 2001) and nonclinical (Arce, Simmons, Lovero, Stein, \& Paulus, 2008; Del-Ben et al., 2005; Harmer, Mackay, Reid, Cowen, \& Goodwin, 2006; Murphy, Norbury, O’Sullivan, Cowen, \& Harmer, 2009) populations. There is less evidence that antidepres- 


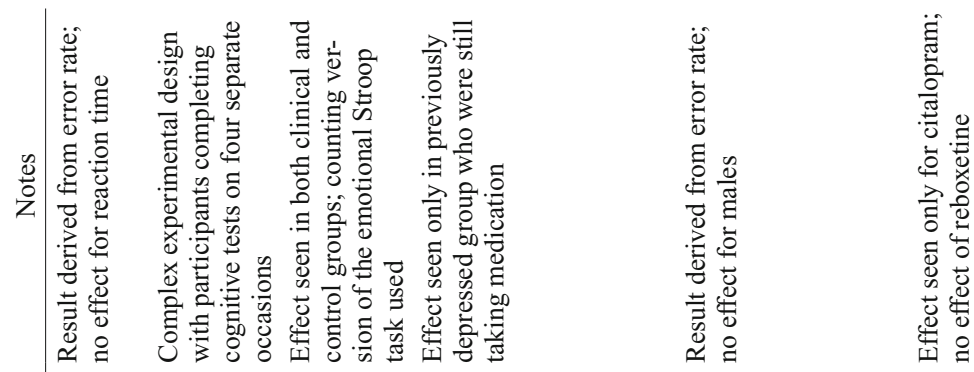

है.

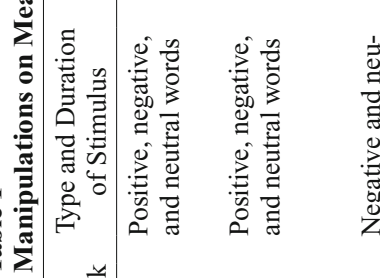

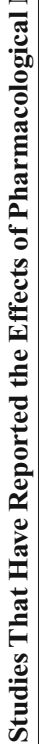

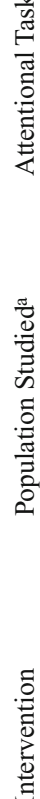

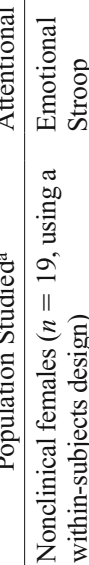

T)

离害

离跤

量䇏

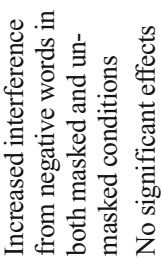

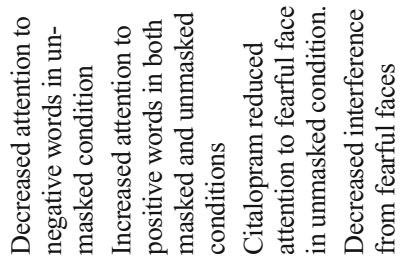

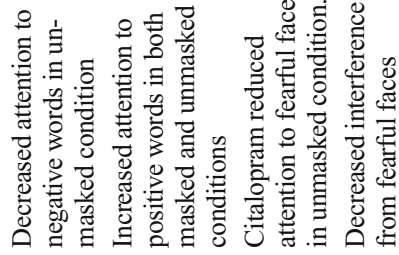
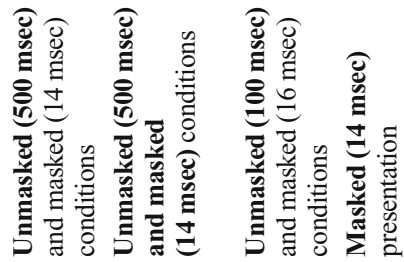

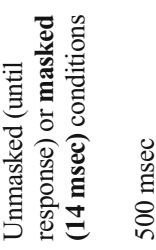

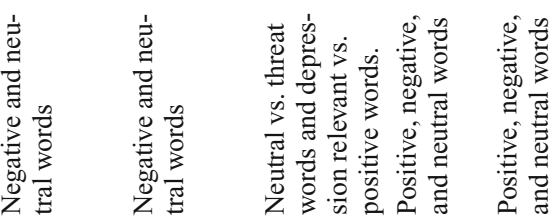

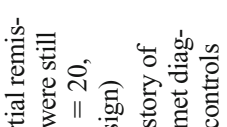

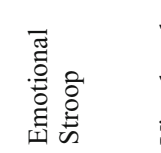

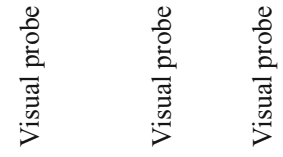

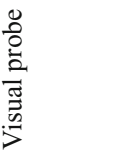

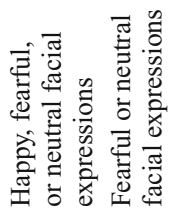

离

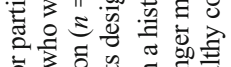

.

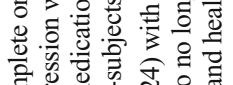

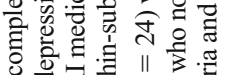

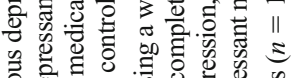

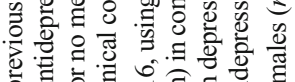

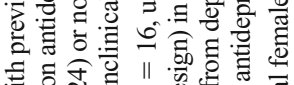

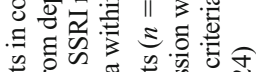

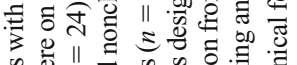

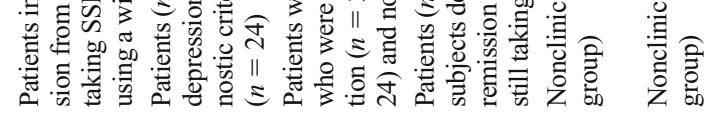

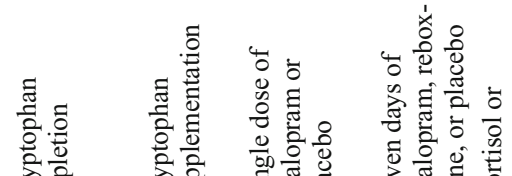

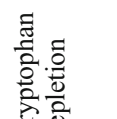

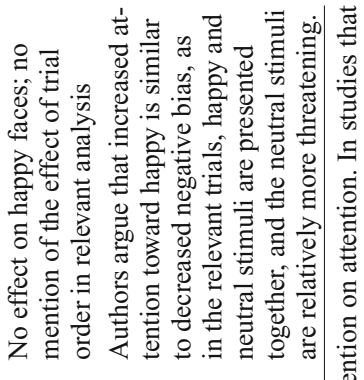

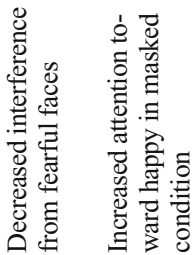
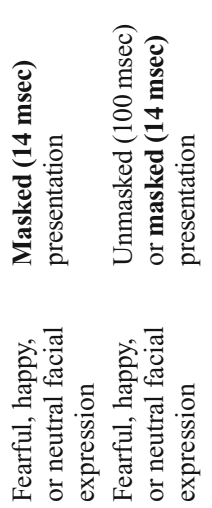

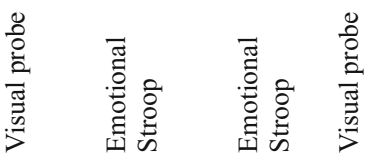

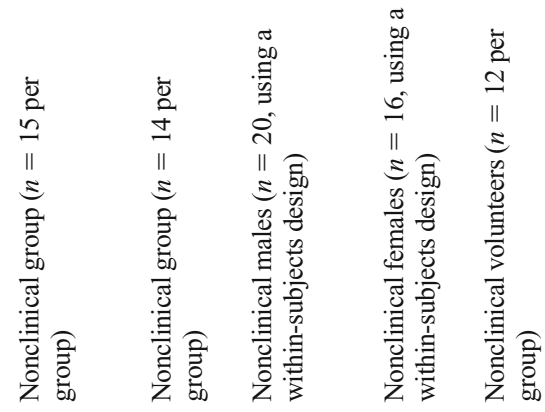

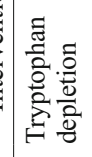

离

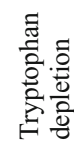

年

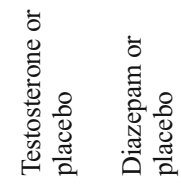

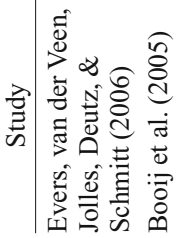

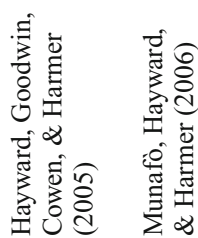

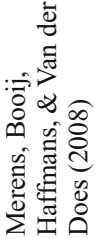

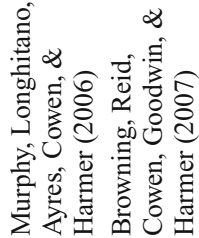

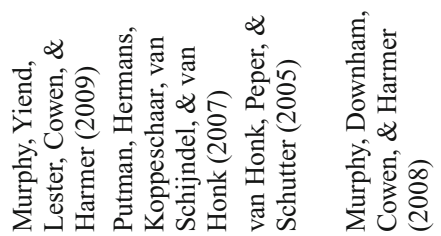

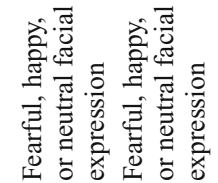


sants alter activity in frontal control regions; two studies reported such an effect (Fales et al., 2009; Kennedy et al., 2001), although both of these involved clinical populations, indicating that the findings may have been secondary to improved clinical status, rather than a treatment effect. An event-related potential (ERP) study has examined the effects of citalopram and reboxetine on the processing of emotional information in healthy volunteers (Kerestes et al., 2009). The high temporal acuity of ERP allowed the authors to demonstrate that both antidepressants influenced processing relatively shortly after stimulus presentation $(250 \mathrm{msec})$, with the effect being found in a component of the ERP known to be sensitive to spatial attention (Eimer, Holmes, \& McGlone, 2003). The neuroimaging findings are thus consistent with an initial effect of antidepressants on the amygdala, with alteration of frontal control regions occurring later on in treatment and potentially reflecting improvement in clinical status. Interestingly, a single study has demonstrated that reboxetine also reduces amygdala activity to negative stimuli (Norbury, Mackay, Cowen, Goodwin, \& Harmer, 2007), despite apparently having no effect on spatial attention to threat (Murphy, Yiend, et al., 2009). A possible explanation of this discrepancy is provided by recent models of norepinephric function that suggest that it acts specifically as a temporal filter in the control of attention (AstonJones \& Cohen, 2005). Thus, the behavioral effects of norepinephric manipulation may best be assessed using measures of the deployment of attention in time, rather than in space. De Martino, Strange, and Dolan (2008) reported a series of three studies that examined the influence of the beta-blocker propranolol and reboxetine on an emotional version of the attentional blink task, which specifically assesses the deployment of attention in time. The authors reported a generally deleterious effect of propranolol on attentional function, in that it caused poorer task performance regardless of stimuli salience. Reboxetine was found to improve task performance, although only on trials involving negative emotional stimuli. No positive stimuli were used in the study, limiting conclusions as to the specificity of reboxetine's effect, although they would be in keeping with its effect on attention being primarily evident in the temporal domain.

Together, these studies indicate that serotonergic antidepressants alter attention to emotional information by encouraging a relatively more positive bias. Again, these effects are associated with an effect of the medication on amygdala function.

Alternative pharmacological strategies. On the basis of clinical findings suggesting that acute administration of glucocorticoids reduces the symptoms of posttraumatic stress disorder (Schelling, Roozendaal, \& De Quervain, 2004), Putman, Hermans, Koppeschaar, van Schijndel, and van Honk (2007) used an emotional Stroop task to demonstrate that a single dose of the glucocorticoid cortisol reduced interference from masked negative stimuli (fearful faces) in healthy men. The same group had previously reported a similar effect when a single dose of testosterone, which has antidepressant activity (Pope, Cohane, Kanayama, Siegel, \& Hudson, 2003), was administered to females (van Honk, Peper, \& Schutter, 2005). Lastly, a single dose of the benzodiazepine diazepam, which has acute anxiolytic effects, has been found to increase attentional bias toward masked happy faces in a nonclinical population (Murphy, Downham, Cowen, \& Harmer, 2008), with a complementary effect of reduced amygdala activation to emotional stimuli being reported for another benzodiazepine, lorazepam (Paulus, Feinstein, Castillo, Simmons, \& Stein, 2005). Thus, a diverse range of medications, all of which have antidepressant or anxiolytic activity, have been found to reduce negative or increase positive attentional bias.

Summary. A number of pharmacological interventions have been shown to alter attention to emotional stimuli. Taken as a whole, the behavioral data suggest that interventions that improve anxiety or depression (tryptophan supplementation, antidepressant medication, steroids, benzodiazepines) tend to result in attention's being directed away from negative and toward positive stimuli. TD, which leads to a worsening of symptoms in vulnerable individuals, tends to have the opposite effect on attention. As can be seen in Table 1, the majority of these effects are seen early on in the deployment of attention, with a number of studies demonstrating an effect with masked stimuli. The timing of the attentional effects suggests that these interventions alter the function of the bottom-up stimulus appraisal system, a conclusion supported by neuroimaging studies in which altered amygdala activity in response to negative stimuli was the most common finding.

\section{Psychological Methods of Modulating Attention to Emotional Information}

Cognitive behavioral therapy (CBT) is a complex psychological intervention that has been developed specifically to change the patterns of thinking and behavior that impact on how individuals interact with the environment and their resulting emotional states (Hollon, Stewart, \& Strunk, 2006). CBT has been recommended as a first-line treatment for both depression and anxiety (NICE, 2004, 2007). A single study examining the effect of CBT on attentional function in anxiety disorder suggested that it reduces the negative attentional bias found pretreatment (Mathews, Mogg, Kentish, \& Eysenck, 1995). However, as was discussed above, such a finding may be attributed to nonspecific effects of clinical status, rather than being regarded as necessarily a direct effect of treatment. Unfortunately, the complexity and variability of CBT can limit the extent to which it may be applied in controlled experimental trials. Perhaps because CBT is difficult to administer in experimental studies, there has been an increasing interest in developing simpler cognitive tasks that target the key hypothesized emotional processes and lend themselves to controlled experimentation. Although many of these tasks involve the explicit and effortful control of emotion (McRae et al., 2010; Ochsner \& Gross, 2005; Phan et al., 2005), a number of techniques have been developed recently to specifically alter the habitual deployment of attention to emotional information (Dandeneau, Baldwin, Baccus, Sakellaropoulo, \& Pruessner, 2007; 


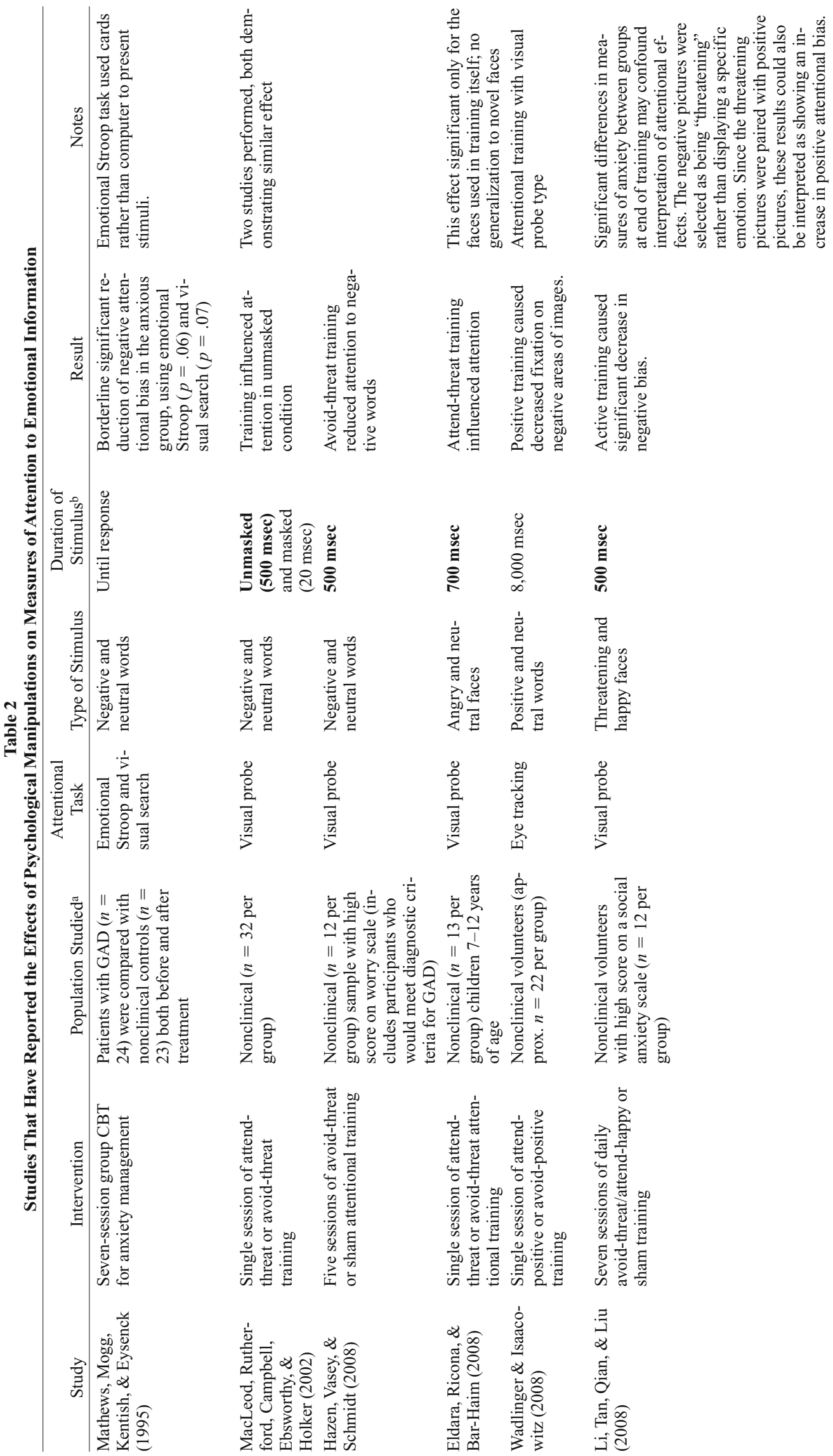




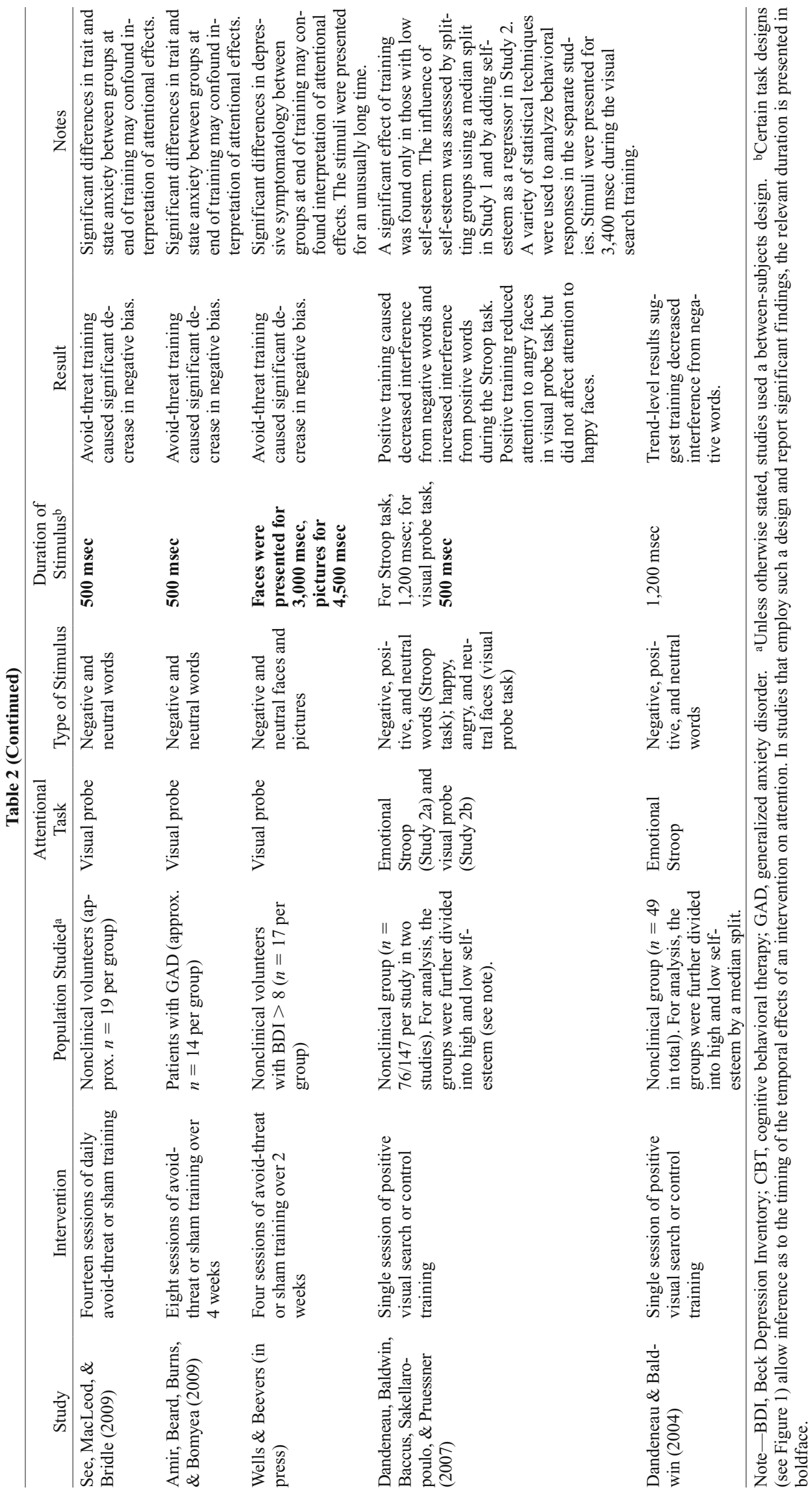


MacLeod, Rutherford, Campbell, Ebsworthy, \& Holker, 2002). The most commonly used technique (e.g., MacLeod et al., 2002) employs a variant of the visual probe task (see Figure 1) in which the location of the probe is constrained such that it always replaces the neutral (for avoid-threat training) or negative (for attend-threat training) word. The task involves many experimental trials, over the course of which participants learn to direct attention toward the type of stimuli that predict the probe location; for example, if the probe always replaces negative stimuli, participants develop the habit of attending to negative stimuli generally (a negative attentional bias). Importantly, there is increasing evidence that using such tasks to encourage a positive attentional bias (avoid-threat training) in clinical populations results in improvement in symptoms (Amir, Beard, Burns, \& Bomyea, 2009; Dandeneau et al., 2007; Eldara, Ricona, \& Bar-Haim, 2008; Hazen, Vasey, \& Schmidt, 2008; Schmidt, Richey, Buckner, \& Timpano, 2009). Concerns about the generalizability and duration of these training effects have, to some extent, been countered by preliminary evidence that the beneficial effects on anxiety symptoms persist for at least 4 months after training (Schmidt et al., 2009). A number of studies have assessed the effects of these socalled attentional training/attentional bias modification tasks on measures of emotional attention (see Table 2) in both clinical and nonclinical populations. Generally, the tasks are seen to influence attention in the manner expected, although, as can be seen from Table 2, they have only been shown to influence attention to those unmasked stimuli presented for $500 \mathrm{msec}$ or longer. A caveat to this observation is that the training tasks themselves generally involve a version of the visual probe task in which stimuli are presented for $500 \mathrm{msec}$, raising the possibility that earlier effects on attention might be observed if the training task was altered to present stimuli for a shorter time. However, the published data to date differ from those involving pharmacological manipulations in which effects are reported during earlier stages of information processing. If this behavioral observation is valid, it suggests that cognitive training tasks and pharmacological interventions may alter distinct mechanisms of attentional control, a hypothesis that has previously been raised by a number of authors (DeRubeis, Siegle, \& Hollon, 2008; Harmer, 2008). We recently completed a neuroimaging study that tested this view; the effect of attentional training in healthy volunteers was assessed (Browning, Holmes, Murphy, Goodwin, \& Harmer, in press), using an fMRI paradigm that varied both emotion and attention (Pessoa, Padmala, $\&$ Morland, 2005). The study indicated a significant effect of the training on activity in the $\mathrm{PFC}$ and rostral ACC, with no effects demonstrable in the amygdala. In keeping with their role in mediating attentional control, activity in the $\mathrm{PFC}$ and ACC was increased specifically when participants' attention was directed in the direction opposite to that encouraged by the training task - that is, when the need for control was high. Interestingly, a number of studies have suggested that the explicit reappraisal of emotion is mediated by changes in similar areas (McRae et al., 2010; Ochsner \& Gross, 2005; Phan et al., 2005). When considered together with the neuroimaging studies reviewed above, in which pharmacological manipulation was seen to alter amygdala activity, these results support the conclusion that cognitive and pharmacological interventions may target distinct processes in the control of emotional attention.

Summary. Cognitive training tasks (also known as cognitive bias modification tasks) have been shown to alter both attention to emotional information and clinical status in a predictable manner, although further studies deploying the experimental tasks in clinical populations are needed. The extant results suggest that this effect occurs later in the deployment of attention than that found with pharmacological manipulations, raising the possibility that different attentional control mechanisms are targeted.

\section{Synthesis}

A variety of techniques have been shown to alter emotional attention in clinical and nonclinical populations. Across all of these methodologies, interventions that improve anxiety and depression also cause attention to be preferentially deployed away from negative and toward positive information. The greatest amount of data is available for the pharmacological manipulation of the serotonergic system and for the use of cognitive attention training tasks. Characterization of the attentional effects of these interventions, using both behavioral and neuroimaging outcomes, suggests that they target different components of the attentional control system. Specifically, pharmacological modifications appear to alter the initial deployment of attention, via an effect on the amygdala-based appraisal system, whereas cognitive training interventions may influence attention some time later, possibly via an effect on frontal control regions.

Implications for treatment. Current evidence supports the efficacy of serotonergic antidepressants in the treatment of both anxiety and depression. Attentional training interventions have initial evidence suggesting efficacy in anxiety (MacLeod et al., 2009) but have yet to be applied to depressed groups (although a single positive study has been reported in a nonclinical dysphoric group; Wells \& Beevers, in press). However, in real-world situations, the ability of either pharmacological or cognitive treatments to induce remission is, at best, moderate (e.g., DeRubeis et al., 2005, reported remission rates of $40 \%-50 \%$ ). A number of studies have examined the combination of psychotherapy and antidepressant medication with mixed results (Foa, Franklin, \& Moser, 2002; Furukawa, Watanabe, \& Churchill, 2007; Pampallona, Bollini, Tibaldi, Kupelnick, \& Munizza, 2004); however, all of these studies have used complex psychotherapeutic interventions, rather than procedures designed to target specific cognitive systems, such as attentional training. An intriguing possibility raised by the observation that antidepressant medication and cognitive training influence distinct information-processing stages is that, if combined, their effects on attention may be additive. If true, this would predict that concurrent 
administration of both interventions in a clinical setting would improve efficacy over either on its own. However, this prediction rests on the untested assumption that the two interventions combine additively. As an alternative, it is conceivable that the learning that underlies the cognitive training task depends on an intact emotional signal provided by the amygdala; that is, in order to train attention to emotional stimuli, the participant must be able to detect the emotional content of the stimulus. If detecting this signal depends on amygdala function, antidepressant treatment, which can interfere with this function, may block the effects of training. A study in which the effects of the combination of these interventions on attentional function were gauged would be relatively simple to design, allowing the competing hypotheses to be tested. Lastly, it is worth noting that a number of alternative augmentation strategies exist that may bolster the effects of attentional training. In particular, D-cycloserine, a partial NMDA agonist, has been shown to facilitate learning, with early studies suggesting that it may be therapeutically useful when combined with psychotherapy (Norberg, Krystal, \& Tolin, 2008; Wilhelm et al., 2008). It has yet to be demonstrated that this agent can augment the acquisition of attentional habits, but were this to be the case, it would seem reasonable to hypothesize that it would increase the efficacy of training.

Are these results relevant to depression? A quick appraisal of the studies summarized in Tables 1 and 2 demonstrates that both pharmacological and psychological manipulations of attention have been assessed using relatively brief stimulus presentations, with all but one of the studies presenting stimuli for $700 \mathrm{msec}$ or less. Consequently, it may be easier to argue that these findings are relevant to anxiety, which is associated with perturbations of early attentional deployment, than that they are relevant to depression, which is associated with later effects (Mathews \& MacLeod, 2005). Indeed, the single study that employed longer presentation times (Wells \& Beevers, in press) presented stimuli for a much longer duration than that reported in the depression studies. It is not necessarily the case that there are no effects at the latencies typically reported for depression; rather, the studies that would assess these effects have yet to be performed or published. If the modification of attention is, indeed, relevant to the treatment of depression, it would be expected that both pharmacological and cognitive interventions would alter attention when measured at 1,000 msec. In addition, as has been suggested by the anxiety literature, reduction of the negative attentional bias measured at $1,000 \mathrm{msec}$, using a training paradigm, would be predicted to improve the symptoms of depression.

Future directions. Although we have focused on using measures of emotional attention to dissect the effects of clinical and experimental interventions, the same measures may also be sensitive to individual differences in genetic risk. For example, the long allele of the promoter region of the serotonin transporter gene (5-HTTLPR), which may confer resistance to emotional disorders (Munafò et al., 2009), has recently been found to be associated with a positive attentional bias (Fox, Ridgewell, \&
Ashwin, 2009). Alterations in measures of attentional bias may thus provide a proxy marker by which both risk factors and treatment can be compared, within subgroups of patients and, ultimately, within a single individual. The identification of intermediate processes, such as attentional bias, which are believed to play a key role in the transition of risk to illness and treatment to response, is an essential first step in tailoring treatments to individual patients. An interesting initial approach to this issue would be to assess the interaction between genotype and attentional modification. Specifically, do particular genotypes increase or decrease the effects of antidepressants and cognitive training on attention?

\section{Conclusion}

In the present review, we have argued that the alteration of attentional bias (assessed using both behavioral and neuroimaging outcomes) is a sensitive, proximal measure of treatment effect for the emotional disorders. We have demonstrated that both pharmacological and cognitive interventions are able to alter attentional biases and that they seem to do so via distinct mechanisms. Future work needs to compare these manipulations directly, using similar outcome measures to understand to what extent they have similar and distinct actions. By unifying our understanding of evidence-based pharmacological and psychological treatments of emotional disorders, recent advances in cognitive-emotional science provide a guiding framework by which such treatments can be rationally combined and developed. This exciting approach offers a theoretically based, clinically informed opportunity to improve treatment efficacy.

\section{AUTHOR NOTE}

M.B. is supported by a Clinical Training Fellowship from the Wellcome Trust (WT081672MA). E.A.H. is supported by a Royal Society Dorothy Hodgkin Fellowship and the Economic and Social Research Council (RES-061-23-0030). C.J.H. is supported by the Medical Research Council (G0301005). Correspondence concerning this article should be addressed to M. Browning, Department of Psychiatry, University of Oxford, Warneford Hospital, Oxford OX3 7JX, England (e-mail: michael.browning@psych.ox.ac.uk).

\section{REFERENCES}

Adolphs, R., Tranel, D., Damasio, H., \& Damasio, A. R. (1995). Fear and the human amygdala. Journal of Neuroscience, 15, 5879-5891.

Algom, D., Chajut, E., \& Lev, S. (2004). A rational look at the emotional Stroop phenomenon: A generic slowdown, not a Stroop effect. Journal of Experimental Psychology: General, 133, 323-338.

Amir, N., Beard, C., Burns, M., \& Bomyea, J. (2009). Attention modification program in individuals with generalized anxiety disorder. Journal of Abnormal Psychology, 118, 28-33.

Arce, E., Simmons, A. N., Lovero, K. L., Stein, M. B., \& Paulus, M. P. (2008). Escitalopram effects on insula and amygdala BOLD activation during emotional processing. Psychopharmacology, 196, 661-672.

Aston-Jones, G., \& Cohen, J. D. (2005). An integrative theory of locus coeruleus-norepinephrine function: Adaptive gain and optimal performance. Annual Review of Neuroscience, 28, 403-450.

BECK, A. T. (1976). Cognitive therapy and the emotional disorders. New York: International University Press.

Bishop, S. J. (2007). Neurocognitive mechanisms of anxiety: An integrative account. Trends in Cognitive Sciences, 11, 307-316. 
Bishop, S. J., Duncan, J., Brett, M., \& Lawrence, A. D. (2004). Prefrontal cortical function and anxiety: Controlling attention to threatrelated stimuli. Nature Neuroscience, 7, 184-188.

Bishop, S. J., Duncan, J., \& Lawrence, A. D. (2004). State anxiety modulation of the amygdala response to unattended threat-related stimuli. Journal of Neuroscience, 24, 10364-10368.

BooiJ, L., Van der Does, A. J. W., Haffmans, P. M. J., Riedel, W. J., FeKkes, D., \& Blom, M. J. B. (2005). The effects of high-dose and low-dose tryptophan depletion on mood and cognitive functions of remitted depressed patients. Journal of Psychopharmacology, 19, 267-275.

BoolJ, L., VAN der Does, A. J. W., \& Riedel, W. J. (2003). Monoamine depletion in psychiatric and healthy populations: Review. Molecular Psychiatry, 8, 951-973.

Bradley, B. P., MogG, K., \& Lee, S. C. (1997). Attentional biases for negative information in induced and naturally occurring dysphoria. Behaviour Research \& Therapy, 35, 911-927.

Browning, M., Holmes, E. A., Murphy, S. E., Goodwin, G. M., \& HARMER, C. J. (in press). Lateral prefrontal cortex mediates the cognitive modification of attentional bias. Biological Psychiatry.

Browning, M., Reid, C., Cowen, P. J., Goodwin, G. M., \& Harmer, C. J. (2007). A single dose of citalopram increases fear recognition in healthy subjects. Journal of Psychopharmacology, 21, 684-690.

Canli, T., Sivers, H., Whitfield, S. L., Gotlib, I. H., \& Gabrieli, J. D. E. (2002). Amygdala response to happy faces as a function of extraversion. Science, 296, 2191.

Carver, C. S., Johnson, S. L., \& Joormann, J. (2008). Serotonergic function, two-mode models of self-regulation, and vulnerability to depression: What depression has in common with impulsive aggression. Psychological Bulletin, 134, 912-943.

CARver, C. S., \& White, T. L. (1994). Behavioral inhibition, behavioral activation, and affective responses to impending reward and punishment: The BIS/BAS scales. Journal of Personality \& Social Psychology, 67, 319-333.

Cools, R., Calder, A. J., Lawrence, A. D., Clark, L., Bullmore, E., \& RobBINS, T. W. (2005). Individual differences in threat sensitivity predict serotonergic modulation of amygdala response to fearful faces. Psychopharmacology, 180, 670-679.

CoOper, R. M., \& Langton, S. R. H. (2006). Attentional bias to angry faces using the dot-probe task? It depends when you look for it. Behaviour Research \& Therapy, 44, 1321-1329.

Dandeneau, S. D., \& Baldwin, M. W. (2004). The inhibition of socially rejecting information among people with high versus low selfesteem: The role of attentional bias and the effects of bias reduction training. Journal of Social \& Clinical Psychology, 23, 584-602.

Dandeneau, S. D., Baldwin, M. W., Baccus, J. R., SakellaroPOUlo, M., \& Pruessner, J. C. (2007). Cutting stress off at the pass: Reducing vigilance and responsiveness to social threat by manipulating attention. Journal of Personality \& Social Psychology, 93, 651-666.

Davis, M., \& Whalen, P. J. (2001). The amygdala: Vigilance and emotion. Molecular Psychiatry, 6, 13-34

Del-Ben, C. M., Deakin, J. F., McKie, S., Delvai, N. A., Williams, S. R., ElLIOTt, R., ET AL. (2005). The effect of citalopram pretreatment on neuronal responses to neuropsychological tasks in normal volunteers: An FMRI study. Neuropsychopharmacology, 30, 17241734.

De Martino, B., Strange, B. A., \& Dolan, R. J. (2008). Noradrenergic neuromodulation of human attention for emotional and neutral stimuli. Psychopharmacology, 197, 127-136.

De Raedt, R., \& Koster, E. H. W. (2010). Understanding vulnerability for depression from a cognitive neuroscience perspective: A reappraisal of attentional factors and a new conceptual framework. Cognitive, Affective, \& Behavioral Neuroscience, 10, 50-70.

DeRubeis, R. J., Hollon, S. D., Amsterdam, J. D., Shelton, R. C., Young, P. R., SAlomon, R. M., ET AL. (2005). Cognitive therapy vs medications in the treatment of moderate to severe depression. Archives of General Psychiatry, 62, 409-416.

DeRubeis, R. J., Siegle, G. J., \& Hollon, S. D. (2008). Cognitive therapy versus medication for depression: Treatment outcomes and neural mechanisms. Nature Reviews Neuroscience, 9, 788-796.

Desimone, R., \& Duncan, J. (1995). Neural mechanisms of selective visual attention. Annual Review of Neuroscience, 18, 193-222.
Donaldson, C., Lam, D., \& Mathews, A. (2007). Rumination and attention in major depression. Behaviour Research \& Therapy, $\mathbf{4 5}$ 2664-2678

Eimer, M., Holmes, A., \& McGlone, F. P. (2003). The role of spatial attention in the processing of facial expression: An ERP study of rapid brain responses to six basic emotions. Cognitive, Affective, \& Behavioral Neuroscience, 3, 97-110.

Eldara, S., Ricona, T., \& Bar-Haim, Y. (2008). Plasticity in attention: Implications for stress response in children. Behaviour Research \& Therapy, 46, 450-461.

Evers, E. A., van der Veen, F. M., Jolles, J., Deutz, N. E., \& Schmitt, J. A. (2006). Acute tryptophan depletion improves performance and modulates the BOLD response during a Stroop task in healthy females. NeuroImage, 32, 248-255.

Fales, C. L., Barch, D. M., Rundle, M. M., Mintun, M. A., Mathews, J., Snyder, A. Z., \& Sheline, Y. I. (2009). Antidepressant treatment normalizes hypoactivity in dorsolateral prefrontal cortex during emotional interference processing in major depression. Journal of Affective Disorders, 112, 206-211.

Fales, C. L., Barch, D. M., Rundle, M. M., Mintun, M. A., Snyder, A. Z., Cohen, J. D., ET AL. (2008). Altered emotional interference processing in affective and cognitive-control brain circuitry in major depression. Biological Psychiatry, 63, 377-384.

Foa, E. B., Franklin, M. E., \& Moser, J. (2002). Context in the clinic: How well do cognitive-behavioral therapies and medications work in combination? Biological Psychiatry, 52, 987-997.

Fox, E., Ridgewell, A., \& Ashwin, C. (2009). Looking on the bright side: Biased attention and the human serotonin transporter gene. Proceedings of the Royal Society B, 276, 1747-1751.

Fox, E., Russo, R., \& Georgiou, G. A. (2005). Anxiety modulates the degree of attentive resources required to process emotional faces. Cognitive, Affective, \& Behavioral Neuroscience, 5, 396-404.

Fu, C. H., Williams, S. C., Cleare, A. J., Brammer, M. J., Walsh, N. D., Kim, J., ET AL. (2004). Attenuation of the neural response to sad faces in major depression by antidepressant treatment: A prospective, event-related functional magnetic resonance imaging study. Archives of General Psychiatry, 61, 877-889.

Furukawa, T. A., Watanabe, N., \& Churchill, R. (2007). Combined psychotherapy plus antidepressants for panic disorder with or without agoraphobia. Cochrane Database of Systematic Reviews, Issue 1, Art. No. CD004364.

Gilboa-Schechtman, E., Erhard-Weiss, D., \& Jeczemien, P. (2002). Interpersonal deficits meet cognitive biases: Memory for facial expressions in depressed and anxious men and women. Psychiatry Research, 113, 279-293.

Gotlib, I. H., Kasch, K. L., Traill, S. K., Joormann, J., Arnow, B. A., \& Johnson, S. L. (2004). Coherence and specificity of information processing biases in depression and social phobia. Journal of Abnormal Psychology, 113, 386-398.

Gotlib, I. H., Krasnoperova, E., Yue, D. N., \& Joormann, J. (2004). Attentional biases for negative interpersonal stimuli in clinical depression. Journal of Abnormal Psychology, 113, 127-135.

Harmer, C. J. (2008). Serotonin and emotional processing: Does it help explain antidepressant drug action? Neuropharmacology, 55, 1023 1028.

Harmer, C. J., Mackay, C. E., Reid, C. B., Cowen, P. J., \& GoodWIN, G. M. (2006). Antidepressant drug treatment modifies the neural processing of nonconscious threat cues. Biological Psychiatry, 59, 816-820.

Hayward, G., Goodwin, G. M., Cowen, P. J., \& Harmer, C. J. (2005) Low-dose tryptophan depletion in recovered depressed patients induces changes in cognitive processing without depressive symptoms. Biological Psychiatry, 57, 517-524.

Hazen, R. A., Vasey, M. W., \& Schmidt, N. B. (2008). Attentional retraining: A randomized clinical trial for pathological worry. Journal of Psychiatric Research, 43, 627-633.

Hollon, S. D., Stewart, M. O., \& Strunk, D. (2006). Enduring effects for cognitive behavior therapy in the treatment of depression and anxiety. Annual Review of Psychology, 57, 285-315.

Joormann, J., \& GotLib, I. H. (2007). Selective attention to emotional faces following recovery from depression. Journal of Abnormal Psychology, 116, 80-85. 
Kennedy, S. H., Evans, K. R., Krüger, S., Mayberg, H. S., Meyer, J. H., McCANN, S., ET AL. (2001). Changes in regional brain glucose metabolism measured with positron emission tomography after paroxetine treatment of major depression. American Journal of Psychiatry, 158, 899-905.

Kerestes, R., Labuschagne, I., Croft, R. J., O’Neill, B. V., BhagWagar, Z., Phan, K. L., \& Nathan, P. I. (2009). Evidence for modulation of facial emotional processing bias during emotional expression decoding by serotonergic and noradrenergic antidepressants: An event-related potential (ERP) study. Psychopharmacology, 202, 621-634.

Knutson, B., Bhanji, J. P., Cooney, R. E., Atlas, L. Y., \& Gotlib, I. H. (2008). Neural responses to monetary incentives in major depression. Biological Psychiatry, 63, 686-692.

Larsen, R. J., Mercer, K. A., \& Balota, D. A. (2006). Lexical characteristics of words used in emotional Stroop experiments. Emotion, 6, 62-72.

Leyman, L., De Raedt, R., Schacht, R., \& Koster, E. H. (2007). Attentional biases for angry faces in unipolar depression. Psychological Medicine, 37, 393-402.

Li, S., TAN, J., QIan, M., \& LiU, X. (2008). Continual training of attentional bias in social anxiety. Behaviour Research \& Therapy, 46, 905-912.

MacDonald, A. W., Cohen, J. D., Stenger, V. A., \& Carter, C. S. (2000). Dissociating the role of the dorsolateral prefrontal and anterior cingulate cortex in cognitive control. Science, 288, 1835-1838.

Macleod, C. M., Campbell, L. W., Rutherford, E., \& Wilson, E. (2004). The causal status of anxiety-linked attentional and interpretive bias. In J. Yiend (Ed.), Cognition, emotion and psychopathology: Theoretical, empirical and clinical directions (pp. 172-189). Cambridge: Cambridge University Press.

MacLeod, C. M., Koster, E. H., \& Fox, E. (2009). Whither cognitive bias modification research? Commentary on the special section articles. Journal of Abnormal Psychology, 118, 89-99.

MacLeod, C. M., Mathews, A., \& TATA, P. (1986). Attentional bias in emotional disorders. Journal of Abnormal Psychology, 95, 15-20.

Macleod, C., Rutherford, E., Campbell, L., Ebsworthy, G., \& HOLKER, L. (2002). Selective attention and emotional vulnerability: Assessing the causal basis of their association through the experimental manipulation of attentional bias. Journal of Abnormal Psychology, 111, 107-123.

Maser, J. D., \& Cloninger, C. R. (1990). Comorbidity of mood and anxiety disorders. Washington, DC: American Psychiatric Press.

Mathews, A., \& Mackintosh, B. (1998). A cognitive model of selective processing in anxiety. Cognitive Therapy \& Research, 22, 539-560.

Mathews, A., \& MacLeod, C. (1985). Selective processing of threat cues in anxiety states. Behaviour Research \& Therapy, 23, 563-569.

Mathews, A., \& MacLeod, C. (2002). Induced processing biases have causal effects on anxiety. Cognition \& Emotion, 16, 331-354.

Mathews, A., \& MacLeod, C. (2005). Cognitive vulnerability to emotional disorders. Annual Review of Clinical Psychology, 1, 167-195.

Mathews, A., Mogg, K., Kentish, J., \& Eysenck, M. (1995). Effect of psychological treatment on cognitive bias in generalized anxiety disorder. Behaviour Research \& Therapy, 33, 293-303.

Mayberg, H. S., Liotti, M., Brannan, S. K., McGinnis, S., MahuRIN, R. K., JERABEK, P. A., ET AL. (1999). Reciprocal limbic-cortical function and negative mood: Converging PET findings in depression and normal sadness. American Journal of Psychiatry, 156, 675-682.

McRae, K., Hughes, B., Chopra, S., Gabrieli, J. D. E., Gross, J. J., \& OChSNer, K. N. (2010). The neural bases of distraction and reappraisal. Journal of Cognitive Neuroscience, 22, 248-262.

Merens, W., BooiJ, L., Haffmans, P. J., \& Van der Does, A. J. W. (2008). The effects of experimentally lowered serotonin function on emotional information processing and memory in remitted depressed patients. Journal of Psychopharmacology, 22, 653-662.

MineKa, S., Watson, D., \& Clark, L. A. (1998). Comorbidity of anxiety and unipolar mood disorders. Annual Review of Psychology, 49, 377-412.

Mogg, K., \& Bradley, B. P. (1998). A cognitive-motivational analysis of anxiety. Behaviour Research \& Therapy, 36, 809-848.

Mogg, K., Bradley, B. P., \& Williams, R. (1995). Attentional bias in anxiety and depression: The role of awareness. British Journal of Clinical Psychology, 34, 17-36.

Munafò, M. R., Freimer, N. B., NG, W., Ophoff, R., Veijola, J., Miettunen, J., ET AL. (2009). 5-HTTLPR genotype and anxietyrelated personality traits: A meta-analysis and new data. American Journal of Genetics, 150B, 271-281.

Munafò, M. R., Hayward, G., \& Harmer, C. J. (2006). Selective processing of social threat cues following acute tryptophan depletion. Journal of Psychopharmacology, 20, 33-39.

Murphy, S. E., Downham, C., Cowen, P. J., \& Harmer, C. J. (2008). Direct effects of diazepam on emotional processing in healthy volunteers. Psychopharmacology, 199, 503-513.

Murphy, S. E., Longhitano, C. L., Ayres, R. E., Cowen, P. J., \& HARMER, C. J. (2006). Tryptophan supplementation induces a positive bias in the processing of emotional material in healthy female volunteers. Psychopharmacology, 187, 121-130.

Murphy, S. E., Norbury, R., O'Sullivan, U., Cowen, P. J., \& Harmer, C. J. (2009). Effect of a single dose of citalopram on amygdala response to emotional faces. British Journal of Psychiatry, 194, 535-540.

Murphy, S. E., Yiend, J., Lester, K. J., Cowen, P. J., \& Harmer, C. J. (2009). Short-term serotonergic but not noradrenergic antidepressant administration reduces attentional vigilance to threat in healthy volunteers. International Journal of Neuropsychopharmacology, 12, 169-179.

NICE (2004). Depression: Management of depression in primary and secondary care. London: Author.

NICE (2007). Management of anxiety (panic disorder, with or without agoraphobia, and generalized anxiety disorder) in adults in primary, secondary and community care (amended). London: Author.

NisbetT, R. E., \& Wilson, T. D. C. (1977). Telling more than we can know: Verbal reports on mental processes. Psychological Review, 84, 231-259.

Norberg, M. M., Krystal, J. H., \& Tolin, D. F. (2008). A metaanalysis of D-cycloserine and the facilitation of fear extinction and exposure therapy. Biological Psychiatry, 63, 1118-1126.

Norbury, R., Mackay, C. E., Cowen, P. J., Goodwin, G. M., \& HARMER, C. J. (2007). Short-term antidepressant treatment and facial processing: Functional magnetic resonance imaging study. British Journal of Psychiatry, 190, 531-532.

NutT, D. J. (2002). The neuropharmacology of serotonin and noradrenaline in depression. International Clinical Psychopharmacology, 17(Suppl. 1), S1-S12.

OCHSNER, K. N., \& Gross, J. J. (2005). The cognitive control of emotion. Trends in Cognitive Sciences, 9, 242-249.

Pampallona, S., Bollini, P., Tibaldi, G., Kupelnick, B., \& MuNIZZA, C. (2004). Combined pharmacotherapy and psychological treatment for depression: A systematic review. Archives of General Psychiatry, 61, 714-719.

Paulus, M. P., Feinstein, J. S., Castillo, G., Simmons, A. N., \& Stein, M. B. (2005). Dose-dependent decrease of activation in bilateral amygdala and insula by lorazepam during emotion processing. Archives of General Psychiatry, 62, 282-288.

Pessoa, L., Padmala, S., \& Morland, T. (2005). Fate of unattended fearful faces in the amygdala is determined by both attentional resources and cognitive modulation. NeuroImage, 28, 249-255.

Phan, K. L., Fitzgerald, D. A., Nathan, P. J., Moore, G. J., Uhde, T. W., \& TANCER, M. E. (2005). Neural substrates for voluntary suppression of negative affect: A functional magnetic resonance imaging study. Biological Psychiatry, 57, 210-219.

Pope, H. G. J., Cohane, G. H., Kanayama, G., Siegel, A. J., \& HudsON, J. I. (2003). Testosterone gel supplementation for men with refractory depression: A randomized, placebo-controlled trial. American Journal of Psychiatry, 160, 105-111.

Posner, M. I., \& Petersen, S. E. (1990). The attention system of the human brain. Annual Review of Neuroscience, 13, 25-42.

Putman, P., Hermans, E. J., Koppeschaar, H., van Schijndel, A., \& VAN HoNK, J. (2007). A single administration of cortisol acutely reduces preconscious attention for fear in anxious young men. Psychoneuroendocrinology, 32, 793-802.

Reilly, J. G., McTavish, S. F., \& Young, A. H. (1997). Rapid depletion 
of plasma tryptophan: A review of studies and experimental methodology. Journal of Psychopharmacology, 11, 381-392.

Ridout, N., Astell, A. J., Reid, I. C., Glen, T., \& O'Carroll, R. E. (2003). Memory bias for emotional facial expressions in major depression. Cognition \& Emotion, 17, 101-122.

Robinson, O., Cools, R., Crockett, M., \& Sahakian, B. (in press). Mood state moderates the role of serotonin in cognitive biases. Journal of Psychopharmacology.

Ruhe, H. G., Mason, N. S., \& Schene, A. H. (2007). Mood is indirectly related to serotonin, norepinephrine and dopamine levels in humans: A meta-analysis of monoamine depletion studies. Molecular Psychiatry, 12, 331-359.

Schelling, G., Roozendaal, B., \& De Quervain, D. J. (2004). Can posttraumatic stress disorder be prevented with glucocorticoids? In R. Yehuda \& B. McEwen (Eds.), Biobehavioral stress response: Protective and damaging effects (Annals of the New York Academy of Sciences, Vol. 1032, pp. 158-166). New York: New York Academy of Sciences.

Schmidt, N. B., Richey, J. A., Buckner, J. D., \& Timpano, K. R. (2009). Attention training for generalized social anxiety disorder. Journal of Abnormal Psychology, 118, 5-14.

Schneider, F., Weiss, U., Kessler, C., Müller-Gärtner, H. W., Posse, S., Salloum, J. B., ET AL. (1999). Subcortical correlates of differential classical conditioning of aversive emotional reactions in social phobia. Biological Psychiatry, 45, 863-871.

SeE, J., MacLeod, C. M., \& Bridle, R. (2009). The reduction of anxiety vulnerability through the modification of attentional bias: A realworld study using a home-based cognitive bias modification procedure. Journal of Abnormal Psychology, 118, 65-75.

Sheline, Y. I., Barch, D. M., Donnelly, J. M., Ollinger, J. M., SnYDER, A. Z., \& Mintun, M. A. (2001). Increased amygdala response to masked emotional faces in depressed subjects resolves with antidepressant treatment: An fMRI study. Biological Psychiatry, 50, 651-658.

Shin, L. M., Rauch, S. L., \& Pitman, R. K. (2006). Amygdala, medial prefrontal cortex, and hippocampal function in PTSD. In R. Rehuda (Ed.), Psychobiology of posttraumatic stress disorder: A decade of progress (Annals of the New York Academy of Sciences, Vol. 1071, pp. 67-79). New York: New York Academy of Sciences.

Shin, L. M., Whalen, P. J., Pitman, R. K., Bush, G., Macklin, M. L., LASKO, N. B., ET AL. (2001). An fMRI study of anterior cingulate function in posttraumatic stress disorder. Biological Psychiatry, 50, 932-942.
Siegle, G. J., Steinhauer, S. R., Thase, M. E., Stenger, V. A., \& CARTER, C. S. (2002). Can't shake that feeling: Event-related fMRI assessment of sustained amygdala activity in response to emotional information in depressed individuals. Biological Psychiatry, 51, 693-707.

Straube, T., Mentzel, H. J., \& Miltner, W. H. (2006). Neural mechanisms of automatic and direct processing of phobogenic stimuli in specific phobia. Biological Psychiatry, 59, 162-170.

Tillfors, M., Furmark, T., Marteinsdottir, I., \& Fredrikson, M. (2002). Cerebral blood flow during anticipation of public speaking in social phobia: A PET study. Biological Psychiatry, 52, 1113-1119. van der Veen, F. M., Evers, E. A., Deutz, N. E., \& Schmitt, J. A. (2007). Effects of acute tryptophan depletion on mood and facial emotion perception related brain activation and performance in healthy women with and without a family history of depression. Neuropsychopharmacology, 32, 216-224.

van Honk, J., Peper, J. S., \& Schutter, D. J. (2005). Testosterone reduces unconscious fear but not consciously experienced anxiety: Implications for the disorders of fear and anxiety. Biological Psychiatry, 58, 218-225.

Vuilleumier, P. (2005). How brains beware: Neural mechanisms of emotional attention. Trends in Cognitive Sciences, 9, 585-594.

WADlinger, H. A., \& IsAaCowitz, D. M. (2008). Looking happy: The experimental manipulation of a positive visual attention bias. Emotion, 8, 121-126.

Wells, T. T., \& Beevers, C. G. (in press). Biased attention and dysphoria: Manipulating selective attention reduces subsequent depressive symptoms. Cognition \& Emotion. doi:10.1080/02699930802652388

Wilhelm, S., Buhlmann, U., Tolin, D. F., Meunier, S. A., Pearlson, G. D., ReESE, H. E., ET AL. (2008). Augmentation of behavior therapy with D-cycloserine for obsessive-compulsive disorder. American Journal of Psychiatry, 165, 335-341; quiz, 409.

Williams, J. M. G., Mathews, A., \& MacLeod, C. (1996). The emotional Stroop task and psychopathology. Psychological Bulletin, 120, 3-24.

Williams, J. M. G., Watts, F. N., MacLeod, C. M., \& Mathews, A. (1997). Cognitive psychology and emotional disorders. New York: Wiley.

(Manuscript received March 30, 2009; revision accepted for publication August 13, 2009.) 